\title{
Modeling of Construction Cost of Villas in Oman
}

\author{
MA Al-Mohsin*a and AS Al-Nuaimi ${ }^{b}$ \\ ${ }^{*}$ a Department of Civil \& Architectural Engineering, College of Engineering, University of Buraimi, Buraimi, Oman \\ ${ }^{b}$ Department of Civil \& Architectural Engineering, College of Engineering Engineering, Sultan Qaboos University, \\ PO Box 33, PC 123, Al-Khoud, Muscat, Sultanate of Oman
}

Received 16 December 2012; accepted 26 November 2013

\begin{abstract}
In this research, a model for estimating construction cost of villas is presented. The model takes into account four major factors affecting villa's cost, namely: built up area, number of toilets, number of bedrooms and the number of stories. A field survey was conducted to collect information required for such model using data collection form designed by the researchers. Information about 150 villas was collected from six well experienced consultants in the field of villa design and supervision in Oman. Collected data was analyzed to develop suggested model which consists of two main levels of estimate. The first level is at the conceptual design stage where the client presents his/her need of space and basic information about the available plot for construction. The second level of cost estimation is carried out after the preliminary design stage where the client has to decide on the finishes and type of structure. At the second level of estimation, the client should be able to decide whether to precede for construction or not, according to his/her budget. The model is general and can be used anywhere and was validated for accepted degree of confidence using the actual cost of the 112 executed villa projects in Oman. The villas included in this study were owned by clients from both high and low income brackets and had different types of finishing material. The developed equations showed good correlation between the selected variables and the actual cost with $\mathrm{R}^{2}=0.79$ in the case of conceptual estimate and $\mathrm{R}^{2}=0.601$ for preliminary estimate.
\end{abstract}

Keywords: Construction cost estimate, Construction cost model, Cost of villas.

$$
\text { نمذجة لتكلفة بناء الفيلات في عمان }
$$

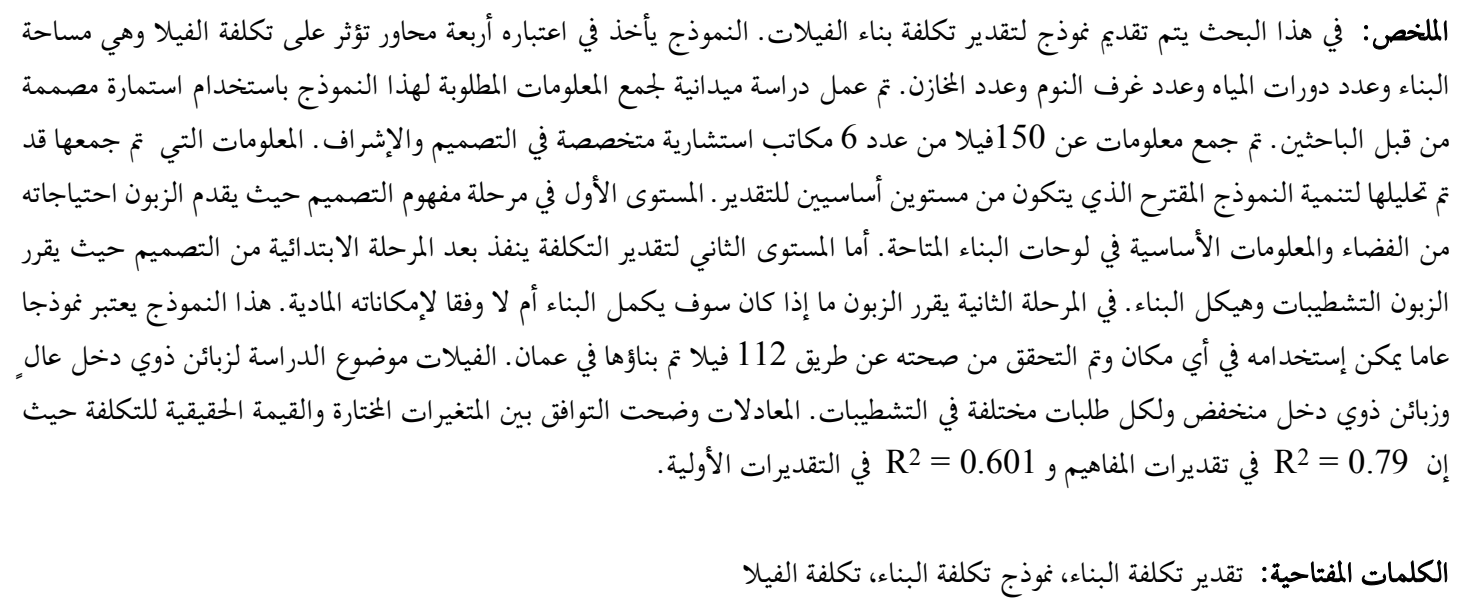




\section{Background}

Large migration of citizens to Muscat, the capital of Oman, and other major cities have resulted in rapid growth of these cities. The good infrastructure, availability of jobs, and good health and educational services encouraged many families to permanently reside in these cities but faced with difficulties in building their own houses due to escalation of construction cost. One of the problems that face families during the design stage of their villas is the knowledge of the construction cost. This research was directed towards development of a simple mathematical model that can be used by large number of people to estimate the construction cost of villas. Villa type of accommodation was selected for this study due to the fact that this type is the most popular accommodation used by Gulf States families. Typical villa constitutes of five bedrooms, two living rooms, one dining hall, one family hall and six toilets. These components are usually distributed into two floors. They covered villas owned by rich and low income people with different types of finishes.

\section{Problem Statement}

One of the most difficult tasks that face designers of villas in Oman is giving an answer to a repeatedly asked question about the construction cost at the first step of design. Usually at this stage, the client is not sure about his/her needs of space and finishes, and has no clear idea about room layout or factors affecting the construction cost. Disputes may occur between the designer and the client by the end of the detailed design when the later discovers that the dream villa cannot be constructed with the budget available. This is because he/she has not been enlightened, before the detailed design stage, with the factors that affect villas' cost. Therefore, it is important to have, at minimum, a guide that can help consultants and quantity surveyors in involving clients and giving them a clear picture of how to strike a balance between the wishes and the affordability.

\section{Literature Review}

Good estimation of construction cost is crucial in projects for budgeting, planning, and compliance with client's available budget. In cost estimation, correct information and proper estimation are significant factors to reach close to accurate cost. Therefore, parametric cost estimation models are very useful in the early stages of a project's life cycle, when little information is known about the project's scope. Adair et al
(1996) suggested a model that possesses a myriad of attributes that combined to form bundles of utilityaffecting attributes that the consumer values. They stated that implications for the valuation process relate to the selection of comparable evidence and the quality of variables that the valuer may need to consider. Kim et al (2004a) examined the performance of Multiple Regression Analysis (MRA), Neural Networks (NNs) and Case-Based Reasoning (CBR) models on 530 historical costs data and 530 projects of residential buildings that were built by general contractors between 1997 and 2000 in Seoul, Korea. They found that the NN estimating model gave more accurate estimating results than the MRA and CBR models. The CBR model gave better results than NN and MRA in long-term use and time versus accuracy tradeoffs. Kim et al (2004b) applied back-propagation network (BPN) model incorporating genetic algorithms (GAs) to construction cost estimation. The model was examined on construction costs of 530 residential buildings constructed in Korea between 1997 and 2000 and the results were compared with a BPN model using trial and error. Factors involved were gross floor area, number of stories, duration of construction, roof types, usage of basement, and finishing grades. Results showed that BPN incorporating GA gave more accurate cost estimation than $\mathrm{BPN}$ with trial and error. In addition, BPN with GA was found to reduce the time and effort in the early stage of project cost estimation. Snomez (2004) used regression method, neural network, and range estimation techniques for conceptual cost estimation of building projects. This work resulted in three linear regression models to identify the significant variables affecting project cost and two neural network models to examine the possible need for nonlinear or interaction terms in the regression model. Touran and Lopez (2006) introduced a system for modeling the cost escalation uncertainty in large multi year construction projects. The system uses a Monte Carlo simulation approach. This system can be used by planners and cost estimators for budgeting the effect of cost escalation in large projects with multi year schedules. Yaman and Tas (2007) developed a generic building cost estimation model based on functional elements for Turkish construction sector projects which can be used in feasibility and schematic design phases. As the number of the similar projects in database is increased, the accuracy of the model is also increased. The software can be used to estimate building cost of residential projects in feasibility and schematic design phases. Aoieong et al. (2008) presented a case study on using Construction Process Cost Model (CPCM), based on Part 1 of the British 
Standard BS6143 - Process cost model (PCM), to monitor the quality of another non-construction/nontechnological process in Hong Kong. The model can also be used as a tool to monitor the "process continual improvement", a requirement stated in the latest (year 2000) version of the ISO 9000 quality management system. Chou (2009) developed a generalized linear model (GLM) of early quantity prediction technique applied to Texas highway projects using a set of project characteristics. The model depends on geometry-related work activities, namely earthwork, pavement and traffic control which were used for continuous project cost tracking. The benefit of this approach is to provide a platform for evolving the preliminary parametric cost estimates to a fully detailed cost management as further information becomes available during project progress. Lee et al. (2011) proposed a schematic cost estimating model (SCEM) which estimates the construction cost of super tall building alternatives. The model uses a simulation mechanism that considers variation in the number of building stories (ie. $\pm 5, \pm 10, \pm 15, \pm 20$ stories). The SCEM was validated through a case study of an actual super tall building. It was found that schematic construction cost increases as the unit cost rate rises due to a low productivity ratio in the case of a higher number of building stories.

It is clear from the above, that different cost models have been developed by researchers for estimation of construction cost in different countries. The aim is to understand and evaluate the factors affecting the cost of construction. The existing cost models varied in their outcomes depending on the objectives, methodology, techniques and influence of variables used in the input. The authors did not find any published work in the literature regarding construction cost estimate or modeling in Oman.

\section{Proposed Model and Methodology}

A villa cost model was developed in the following sequence:

1. From literature (Kim et al. 2004b and Snomez 2004) ten factors affecting cost models of villas were identified as shown in Table 1. These factors were chosen as variables to build the model for estimating the construction cost of villas.

2. Theoretical basis of cost modeling, definition of the factors affecting the cost of construction and correlation between these factors was carried out.

3 . The data required to build the cost model was collected by carrying out field survey. All factors defined in the first step are now forming the basis of data collection form designed by the researchers. Data collection forms were distributed to 150 selected consultants. The consultants were asked to fill up the predesigned form using the records of
Table 1. Factors identified to cause effect on villa's construction cost.

\begin{tabular}{cl}
$\begin{array}{c}\text { Variable } \\
\text { No. }\end{array}$ & \multicolumn{1}{c}{ Factor } \\
\hline 1 & Built up area \\
2 & Number of bathrooms \\
3 & Number of bed rooms \\
4 & Number of stories (floors) \\
5 & Number of corners (shape effect) \\
6 & Quality of Internal finishes \\
7 & Quality of external finishes \\
8 & Quality of electrical installation \\
9 & Quality of mechanical installation \\
10 & Quality of sanitary installation \\
\hline
\end{tabular}

design and construction of each villa. The selected consultants were well known in the field of villa design in Oman. To ensure clear understanding and correct data filled from the source, trained representatives of the researchers guided the consultants during this process until completion. Data collected through this step was crucial for model building and therefore, care was taken to use only accurately recorded information. This has resulted in only 112 villa records to be considered in the analysis out of the 150 records collected. In addition, some abnormal recorded cases were ignored due to the involvement of variables that were not considered in the model. These eliminated cases were later found to have no effect on the degree of confidence in the model results.

4. Multiple linear regression analysis, using Minitab Software, was carried out to formulate the cost model. The effect of each variable was added to the model separately until a degree of confidence was achieved then a new variable is added and so on. This analysis was carried out on random sample of villas. It was found from the analysis that only four variables out of the ten were causing significant effects on the cost of villa construction and therefore the other six variables were excluded from the model.

5. The model was validated on all of the 112 constructed villas in the year 2008 and results were judged based on compliance to actual recorded costs. Table 2 shows number of records collected from each consultant. To ensure the degree of con-

Table 2. Research records collected from different consultants.

\begin{tabular}{cc}
\hline $\begin{array}{c}\text { Consultant } \\
\text { ID }\end{array}$ & $\begin{array}{c}\text { Number of } \\
\text { records }\end{array}$ \\
\hline 1 & 28 \\
2 & 21 \\
3 & 28 \\
4 & 14 \\
5 & 7 \\
6 & 14 \\
\hline
\end{tabular}


Table 3. Typical ANNOVA table.

\begin{tabular}{cccccc}
\hline Source & SS & DF & MS & F & p \\
\hline Treatments & SST & $\mathrm{k}-1$ & SST / (k-1) & MST/MSE & \\
Error & SSE & N-k & SSE / (N-k) & & \\
Total (corrected) & SS & N-1 & & & \\
\hline
\end{tabular}

Table 4. Degree of correlation of each variable with the actual construction cost of villa.

\begin{tabular}{clc}
\hline $\begin{array}{c}\text { Variable } \\
\text { No. }\end{array}$ & \multicolumn{1}{c}{ Factor } & $\begin{array}{c}\text { Corr elation } \\
\text { actual cost }\end{array}$ \\
\hline 1 & Built up area & 0.617 \\
2 & Number of bathro oms & 0.602 \\
3 & Number of bed rooms & 0.561 \\
4 & Number of stories (floors) & 0.46 \\
5 & Number of corners (shape effect) & 0.385 \\
6 & Quality of Internal finishes & 0.095 \\
7 & Quality of external finishes & 0.047 \\
8 & Quality of electrical installation & -0.106 \\
9 & Quality of mechanical installation & -0.139 \\
10 & Quality of sanitary installation & -0.117 \\
\hline
\end{tabular}

fidence for developed model, ANNOVA analysis was conducted using arithmetical operations as shown in Table 3 as well as calculating the coefficient of multiple regression $\mathrm{R}^{2}$.

N: total number of observations, $\mathbf{k}$ : total number of populations being analyzed, SS: sum of squares treatment, DF: degree of freedom, SST: sum of squares treatment, SSE: sum of squares error, MS: mean square

\section{Correlation between Actual Cost and Relevant Factors (Variables)}

Table 4 shows the correlation coefficient of each variable on the construction cost of villa. Each factor's coefficient shows how much does that factor influence the relationship to the actual cost individually. It is clear from Table 4 that only the first five variables are highly affecting the cost of construction with a good coefficient of correlation. Therefore, the effects of the last five factors were excluded. In addition, the number of corners with correlation factor of 0.385 was neglected after studying the drawings of each villa, and found to be difficult to consider. Also, the number of corners may be misleading as some corners are made for ornamental purposes and have little effect on the external wall/floor area ratio. Therefore, the effects of this factor were also excluded in the development of the model. The remaining three factors significantly affecting the cost of villa construction were plotted in Figs. 1 - 3.

Due to the above findings, the ten factors have been classified into three categories based on the coefficient of correlation as follows:

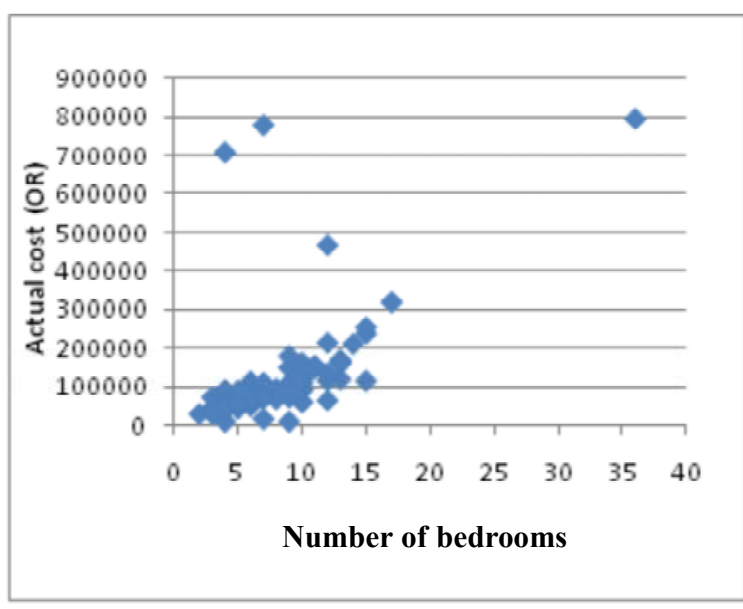

Figure 1. Relationship between actual cost and Number of bedrooms.

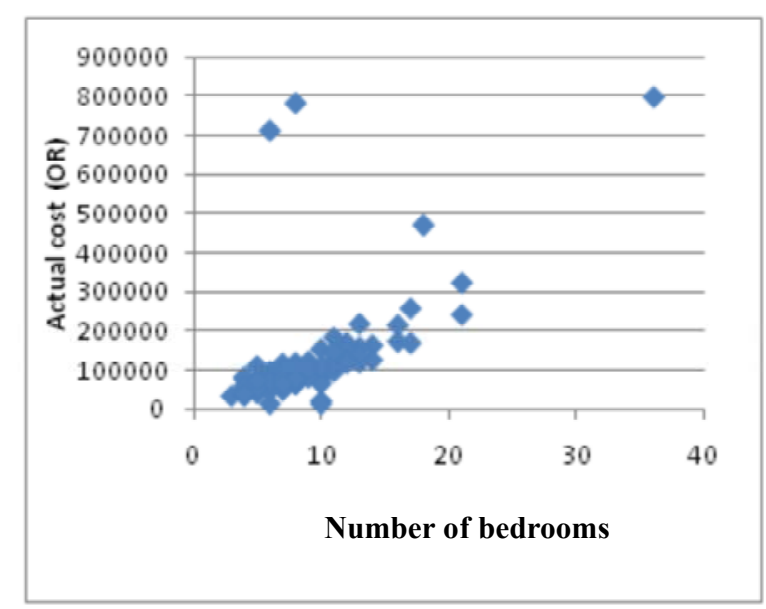

Figure 2. Relationship between actual cost and Number of bathrooms. 


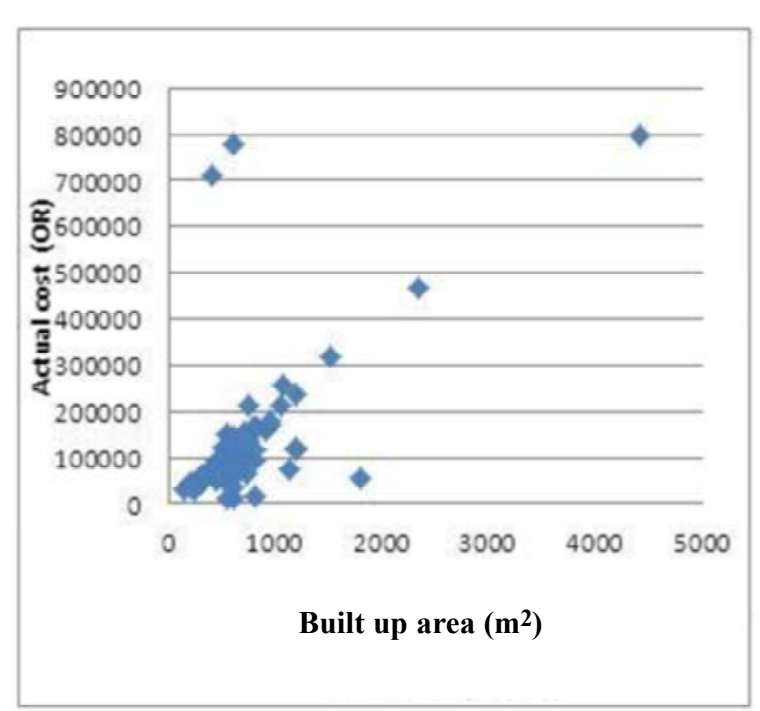

Figure 3. Relationship between actual cost and builtup area.

1. High correlated factors including number of bathrooms, number of bedrooms, and built up area are shown in the Figs. 1-3. These factors constitute the main function of villas for living.

2. Medium correlated factors consist of number of stories and number of corners (as a function of villa shape) as presented in Table 4 . These factors present less degree of correlation with actual cost.

3. Low correlated factors (the last five factors in Table 4): the remaining factors with low coefficient of correlation or near zero towards actual cost.

In addition, correlation was improved by excluding the unusual (outliers) cases related to number of bathrooms, which reached 0.845 after the exclusion of four outliers cases as shown in Fig. 1. The correlation between actual cost and number of bedrooms was also increased to 0.887 after exclusion of the same unusual cases shown in Fig. 2 as hollow points. These increases brought these two factors to be the most effective ones on the cost of villa and development of the cost model.

\section{Model Building}

In order to develop the cost model, many regression trials were carried out to simulate the behavior of villa cost with respect to the factors affecting this cost. These trials resulted in many different equations. The aim was to develop two cost predicting equations that consist of independent factors affecting the cost of villa. The first equation is required at the conceptual stage where the client has some ideas of number of bedrooms, number of bathrooms, and number of stories. The second equation comes at the preliminary stage after the client has finalized the number of bedrooms, number of bathrooms, and number of stories and is ready to discuss the total built up area. The target equations must be in an accepted degree of confidence according to the analysis of variance and $\mathrm{R}^{2}$ value. At both stages, the decision is left to the client based on his/her budget and desire.

Equation 1 shows the first trial with accepted degree of confidence. The analysis of variance is shown in Table 5.

$\operatorname{Cost}($ R.O $)=-38200+262 F 1+15961 F 2+4608 F 3$

Where:

$$
\begin{array}{lll}
F 1 & = & \text { No. of bedrooms } \\
F 2 & = & \text { No. of bathrooms } \\
F 3 & = & \text { No. of stories } \\
F 1, F 2, & \text { and } F 3 \neq & 0 \\
\mathrm{R}^{2}= & 0.363
\end{array}
$$

Despite that the analysis of variance shows less probability to error but still Eqn. 1 is not true representative due to low value of $\mathrm{R}^{2}$ which was 0.363 . In addition, Eqn. 1 is suffering from some weak points such as inability to calculate an estimate when number of bathrooms or number of bedrooms is less than 2 . Therefore, further development with different trials led to a second model represented by Eqn. 2. The second model is an improved version of the first one which was developed by exclusion of 24 unusual cases from the collected data that caused disturbance to the first model.

Cost (R.O.) $=393+2714 F 1+7284 F 2+3797 F 3$

$\mathrm{R}^{2}=0.79$

The second model yields higher value for $\mathrm{F}$ value (as shown in Table 6) and high value for $\mathrm{R}^{2}$ compared to the first model. The second model can be used to estimate the cost of villas in Oman at the conceptual stage. Based on the decision that can be made by the client at this stage, the designer can/cannot proceed to the next stage, ie. the preliminary stage.

Another estimation must be done when the client has decided to proceed in construction of his villa. The next step will be sketching the villa for the client to start another type of estimate using built up area. Equation 3 represents the relationship between the estimated cost and built up area, Table 7 shows ANNOVA analysis for Eqn. 3.

Cost (R.O.) $=-3801+170$ built up area $\mathrm{R}^{2}=0.601$

Estimates made using Eqn. 3 will be more accurate than those made during the conceptual stage using Eqn. 2 because the independent variable which is built up area is closer to reality. The analysis of variance 
Table 5. Analysis of variance (ANNOVA table) for equation.

\begin{tabular}{lllccc}
\hline Source & \multicolumn{1}{c}{ DF } & \multicolumn{1}{c}{ SS } & MS & F & P \\
\hline Regression & 3 & $6.21269 \mathrm{E}+11$ & $2.07090 \mathrm{E}+11$ & 20.48 & 0.000 \\
Residual Error & 108 & $1.09232 \mathrm{E}+12$ & 10114099342 & & \\
Total & 111 & $1.71359 \mathrm{E}+12$ & & & \\
\hline
\end{tabular}

Table 6. Analysis of variance (ANNOVA table) for equation 2.

\begin{tabular}{lcclcc}
\hline \multicolumn{1}{c}{ Source } & DF & \multicolumn{1}{c}{ SS } & \multicolumn{1}{c}{ MS } & F & P \\
\hline Regression & 3 & 77079213208 & 25693071069 & 105.39 & 0.000 \\
Residual Error & 84 & 20478072374 & 243786576 & & \\
Total & 87 & 97557285582 & & & \\
\hline
\end{tabular}

Table 7. Analysis of varianece (ANNOVA table) for equation 3.

\begin{tabular}{lccccc}
\hline Source & DF & SS & MS & F & P \\
\hline Regression & 1 & $1.62819 \mathrm{E}+11$ & $1.62819 \mathrm{E}+11$ & 152.38 & 0.000 \\
Residual Error & 101 & $1.07919 \mathrm{E}+11$ & 1068505881 & & \\
Total & 103 & $2.70738 \mathrm{E}+11$ & & & \\
\hline
\end{tabular}

and $\mathrm{R}^{2}$ value shows the degree of significance of this equation which is acceptable to be the model in its second stage. Figure 4 shows a flowchart of detailed procedure of developed cost model. The proposed model given in Fig. 4 is general and can be used at the early stage of design before the engagement of detail design. The proposed model given in Fig. 4 is general and can be applied anywhere while the estimated costs from Eqns. 2 and 3 are valid anywhere, with base year 2008, provided that consideration is made to the effect of inflation and application of appropriate currency rate.

\section{Results and Discussion}

As shown above, it is clear that only few effective factors caused major changes in the villa construction cost namely; number of bedroom, number of bathroom, number of stories, and built up area, while the rest of factors had negligible effects or were impractical to include. The effects of the first three independent factors come at the conceptual stage and utilized in Eqn. 2 while Eqn. 3 included the effect of the independent factor, built up area. The less effective factors were eliminated from the model development due to the following:

1. Inclusion of any of these factors led to reduction in the degree of confidence in the equations developed which violates the research objectives.

2. Factors appeared in the model as independent variables represent statistically the most effective factors at the same time they were the most affective logically and practically. The main use of villas is for living and the most expensive finishes are required for bedrooms and bathrooms. This point gives the developed equation high solidarity to represent a cost model for villas in Oman.
3. Avoiding the possibility of multicollinearity between the main factors and those of low correlation ones, (multicollinearity is an internal correlation between independent variables).

4. The availability of some unusual cases that might affect results and then reduce the accuracy of the model.

The main outcome of this research was the development of equations which can be considered as mathematical model to estimate villas' construction costs. The proposed model consists of two stages; the first is using Eqn. 2 which is the initial step towards the design and construction of the villa while the second step is an estimate using Eqn. 3 which finalizes the approximate estimate of the villa.

Equation 2 summarizes the main factors affecting cost of villas represented by number of bedrooms, number of bathrooms, and number of floors. These independent factors are the answer to the first question usually asked by consultants to any client before they start the design process. Equation 3 utilizes the knowledge developed of the independent factor, built up area, after finalizing the previous independent factors.

The detailed estimated cost will be dependent on the decisions made during these stages. Detailed estimate is made after completion of design drawings, specifications, and bill of quantities. Progress in design and then construction without such approximate estimates can lead to many risks of stoppage, loss of consultancy fees, delay in construction and disputes.

\section{Sensitivity Analysis}

A sensitivity analysis was carried out to investigate 


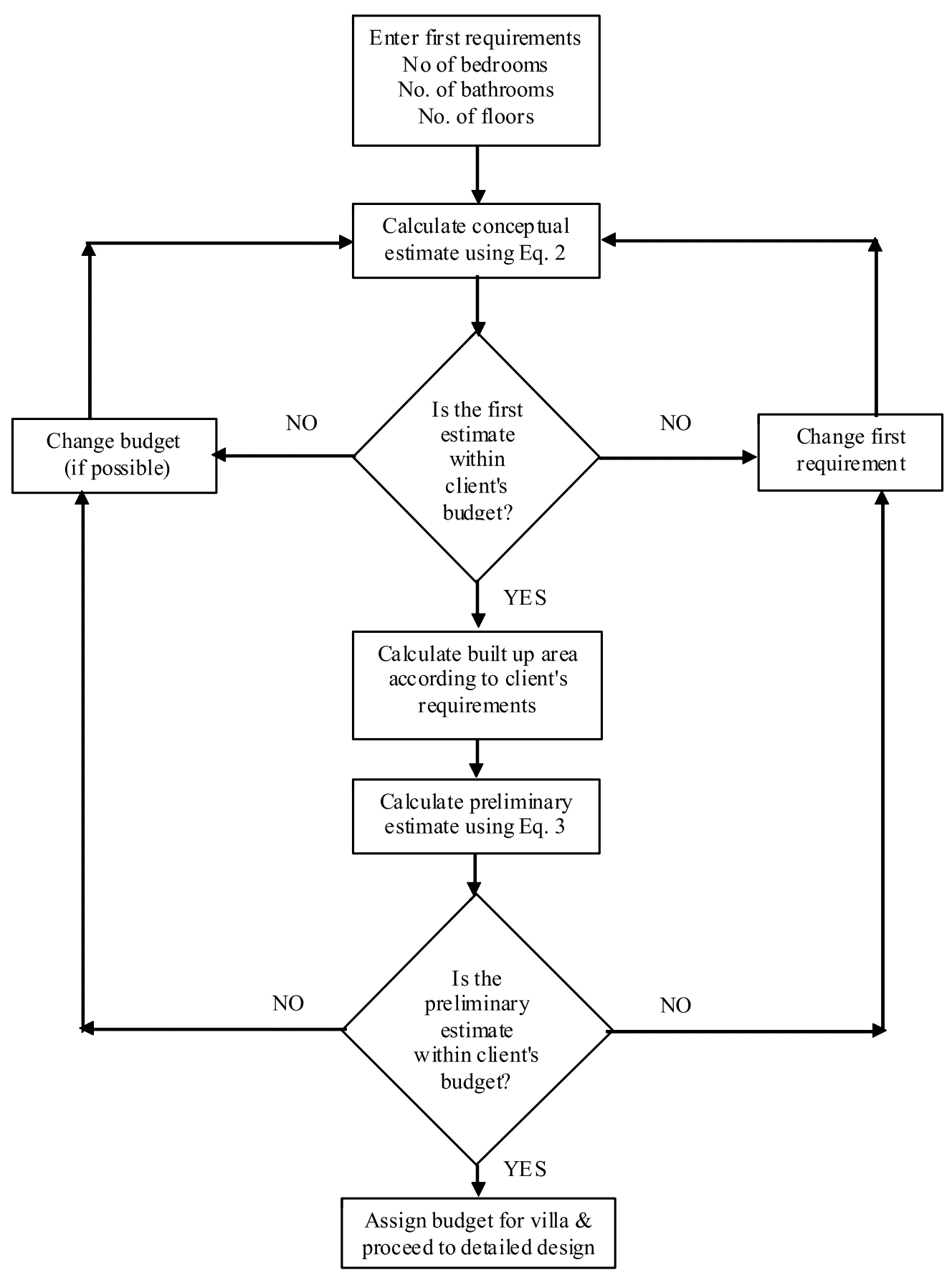

Figure 4. Suggested cost model.

the effects of changing individual variables on estimated cost of villa. Table 8 shows results of a sample of sensitivity analysis calculation. The detailed input and output of this sample is shown in Appendix.

The results of sensitivity analysis showed that the estimated cost in villas is highly affected by the change of number of bathrooms. The increase of cost is proportional to the increase of the number of bathrooms. On the other hand, increasing the number of bedroom has a limited effect on estimated cost with a percentage of about $5 \%$ approximately. Figure 5 shows linear increase in cost in relations to the increase in the number of bathrooms and number of bedrooms. It is clear that the effect of increase in 
Table 8. Effect of changing number of bedrooms and number, number of bathrooms on the estimated cost.

\begin{tabular}{ccccc}
\hline $\begin{array}{c}\text { Estimated cost } \\
(\mathbf{O R})\end{array}$ & $\begin{array}{c}\text { No. of } \\
\text { be drooms }\end{array}$ & $\begin{array}{c}\text { No. of } \\
\text { bathrooms }\end{array}$ & $\begin{array}{c}\text { No. of } \\
\text { floors }\end{array}$ & $\begin{array}{c}\% \text { increase in act ual cost } \\
\text { from previous case }\end{array}$ \\
\hline \multicolumn{6}{c}{ Change of actual cost due to Number of bathrooms } \\
\hline 43301 & 5 & 3 & 2 & 16.74 \\
50549 & 5 & 4 & 2 & 14.34 \\
57797 & 5 & 5 & 2 & 12.54 \\
65045 & 5 & 6 & 2 & 11.14 \\
72293 & 5 & 7 & 2 & \\
\hline 52369 & Change of actual cost due to Number of bedrooms \\
55083 & 3 & 5 & 2 & 4.18 \\
57797 & 4 & 5 & 2 & 4.70 \\
60511 & 5 & 5 & 2 & 4.49 \\
\hline 63225 & 6 & 5 & 2 \\
\hline
\end{tabular}

\section{Effects of Number of bathrooms/bedrooms on construction cost of villa}

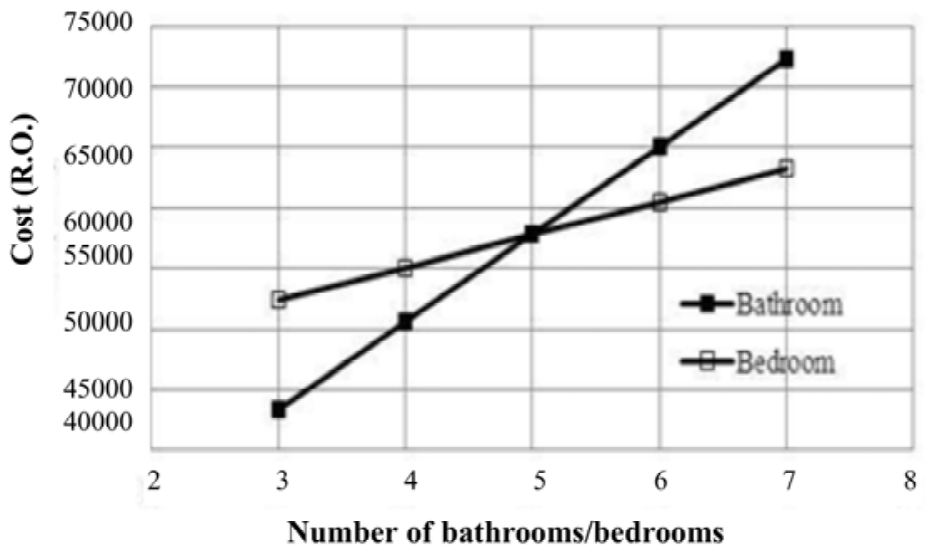

Figure 5. Comparison of results.

bathrooms is steeper than the effect of the increase of bedrooms. Logically the results of sensitivity analysis seem to be accepted because the actual cost for bathroom highly affects the total cost of any villa due to the special requirement in finishing and sanitary works beside other requirements. These requirements are not needed for bedroom and therefore do not have large effect on the construction cost.

\section{Comparison between the Proposed Model and other Existing Models}

The suggested model is differentiated from other models described earlier by the fact that this model is made of collective main factors affecting the construc- tion cost of villas while the approaches of others are made of functional elements of cost and escalation of uncertainty of multi-layer projects. In addition, the model is simple and carries out multi estimate checks that help reducing problems faced by clients and consultants. Figure 5 shows results for many trials with respect to many data entered to Eqn. 2, the result show the clear increase in cost due to increase in number of bathrooms as compared with number of bedrooms.

\section{Conclusions}

Based on the findings of this research, the most effective factors that influence construction cost namely: number of bedrooms, number of bathrooms, and total built up area were used as variables in the devel- 
opment of a numeric construction cost model. The model predicted cost estimates showed good correlation with actual costs of 112 villas used in the research. The model allows the client to decide whether to proceed or not, based on budget or other reasons, at the conceptual stage using Eqn. 2, as the first step and at the preliminary design stage using Eqn. 3. After passing these two estimates, the consultant can proceed to detailed design. The model is general and can be used anywhere while the estimated costs from Eqns. 2 and 3 are valid anywhere, with base year 2008, provided that consideration is made to the effect of inflation and location, and applying appropriate currency rate.

It is recommended to further develop this model to include factors that were not included in this research such as:

1. Adding more variables including time and the geographical location of villa.

2. More data is required to be able to categorize villas based on sizes of bathrooms compared to bedrooms which may lead to filtration and improvement of the model.

\section{References}

Adair AS, Berry JN, McGreal WS (1996), Hedonic modeling housing submarkets and residential valuation, Journal of Property Research 13(1):67-83.

Aoieong RT, Tang SL, Chuck YH (2008), Construction process cost model (CPCM), Proc. First International Conference on Construction In Developing Countries (ICCIDC-I) "Advancing and Integrating Construction Education, Research and Practice" Karachi, Pakistan, 4-5 March, 425434.

Chou JS (2009), Generalized linear model-based expert system for estimating the cost of transportation projects. Expert Systems with Applications 36(3):4253-4267.

Kim G.H, An SH, Kang KI (2004a), Comparison of construction cost estimating models based on regression analysis, neural networks, and casebased reasoning. Building and Environment 39(10):1235-1242.

Kim GH, Yoon JE, An SH, Cho HH, Kang KI (2004b), Neural network model incorporating a genetic algorithm in estimating construction costs. Building and Environment 39(11):1333-1340.

Lee JS, Lee HS, Park MS (2011), Schematic cost estimating model for super tall buildings using a highrise premium ratio. Canadian Journal of Civil Engineering 38(5):530-545.

Sonmez R (2004), Conceptual cost estimation of building projects with regression analysis and neural networks, Canadian Journal of Civil Engineering 31(4):677-683.

Touran A, Lopez R (2006), Modeling cost escalation in large infrastructure projects. Journal of Construction Engineering and Management, ASCE 132(8):853-860.

Wong LT (2002), A cost model for plumbing and drainage systems. Facilities journal 20(11/12):386-393.

Yaman H, Tas E (2007), A building cost estimation model based on functional elements. Istanbul Technical University 4(1):73-87. 


\section{Appendix}

\begin{tabular}{ccccccccc}
\hline $\begin{array}{c}\text { No. of } \\
\text { bed roo ms }\end{array}$ & $\begin{array}{c}\text { No. of } \\
\text { bath room }\end{array}$ & $\begin{array}{c}\text { No. of } \\
\text { floors }\end{array}$ & $\begin{array}{c}\text { Cost } \\
\text { estimate } \\
\text { using Eq. } \\
\mathbf{2}\end{array}$ & $\begin{array}{c}\text { Actual cost } \\
\text { (R.0.) }\end{array}$ & $\begin{array}{c}\text { \% error } \\
\text { through } \\
\text { Eq. 2 }\end{array}$ & $\begin{array}{c}\text { Built up } \\
\text { area } \\
\left(\mathbf{m}^{2}\right)\end{array}$ & $\begin{array}{c}\text { Cost } \\
\text { estimate } \\
\text { using Eq. 3 } \\
\text { (R.O.) }\end{array}$ & $\begin{array}{c}\text { \% error } \\
\text { using } \\
\text { Eq. 3 }\end{array}$ \\
\hline 7 & 6 & 2 & 68616 & 75000 & -8.512 & 450 & 72699 & -3.068 \\
7 & 8 & 2 & 100538 & 109000 & -7.7633 & 545 & 88849 & -18.4872 \\
5 & 7 & 2 & 84053 & 91000 & -7.63407 & 500 & 81199 & -10.7703 \\
10 & 7 & 3 & 89971 & 95000 & -5.29368 & 450 & 72699 & -23.4747 \\
6 & 8 & 1 & 95668 & 99000 & -3.36566 & 550 & 89699 & -9.39495 \\
4 & 6 & 2 & 67830 & 70000 & -3.1 & 400 & 64199 & -8.28714 \\
6 & 8 & 2 & 100276 & 103000 & -2.64466 & 600 & 98199 & -4.66117 \\
17 & 21 & 3 & 315259 & 320000 & -1.48156 & 1522 & 254939 & -20.3316 \\
6 & 8 & 2 & 100276 & 100000 & 0.276 & 600 & 98199 & -1.801 \\
9 & 8 & 3 & 105670 & 105000 & 0.638095 & 612 & 100239 & -4.53429 \\
7 & 9 & 1 & 111891 & 110000 & 1.719091 & 570 & 93099 & -15.3645 \\
13 & 12 & 3 & 170562 & 165000 & 3.370909 & 827 & 136789 & -17.0976 \\
3 & 4 & 1 & 31038 & 30000 & 3.46 & 250 & 38699 & 28.99667 \\
10 & 12 & 3 & 169776 & 163260 & 3.99118 & 816 & 134919 & -17.3594 \\
6 & 8 & 2 & 100276 & 95000 & 5.553684 & 550 & 89699 & -5.58 \\
6 & 8 & 2 & 100276 & 93000 & 7.823656 & 550 & 89699 & -3.54946 \\
4 & 7 & 1 & 79183 & 72000 & 9.976389 & 400 & 64199 & -10.8347 \\
\hline
\end{tabular}

